\title{
How to regain lost leadership
}

\section{The United States is making heavy weather of recasting its distant plans for the exploration of space, chiefly because it seeks leadership without asking what is meant by leadership.}

A fractured leg may prevent a person from walking about, but the frustration it engenders can also be a powerful stimulant of ambitious plans for future expeditions. This seems to be the spirit in which the United States, with the space shuttle still grounded, is asking itself insistently where it will go next. Mars? Back to the Moon? Or somewhere else? There is nothing reprehensible about the cheerful confidence in the future which these questions imply; the shuttle will indeed be flying again one day, probably even more successfully than in the two years preceding the accident at Cape Canaveral eighteen months ago. Then there will be the space station to build, enough to keep people busy for much of the 1990 s. Public and much private imagination in the United States centres on what will happen after that. The down-to-earth report to NASA (National Aeronautics and Space Administration) from Ms Sally Ride, the astronaut, which has now been issued (see Nature 328, 284; 1987), should help to ground fevered speculation in substance.

In practical terms, the recommendations seem derived from the motto "Do not try to run before you can walk!" Specifically, the report concludes that the expedition to Mars, for which there has recently been a groundswell of imperfectly-informed support, is not an option in its own right, but is instead dependent on the development of technology and techniques for doing less spectacular things reliably. To get to Mars safely, people will have to practise getting to the Moon. To do either, as well as to prepare for an uncertain future, there will have to be more deliberate attempts to stimulate new technology. Meanwhile, there is a great deal to be learned about the Solar System from a rounded programme of observation such as that which the planetary science community has been urging on NASA for several years. Ride, who is off to Stanford soon, will find that her report has won her friends in her new workplace.

But why do any of these things? And will any of them assuage the yearning to regain "leadership" in space sharpened by the Challenger disaster? The Ride report takes up this question only obliquely, providing again a list of choices of what meaning can be read into the concept of leadership in much the spirit that a Congregational minister will offer his congregations a choice between alternative concepts of the deity. Ride's caution is not merely forgiveable but understandable. While some small part of the $\$ 10,000$ million a year that NASA spends may be justifiable on utilitarian grounds (telecommunications and so on), and some other small part is comparable with what governments spend on basic research of different kinds, most of this considerable sum is aimed at less tangible goals whose choice is ultimately political, and on which the US administration and the Congress will eventually decide. (The Ride report, as predicted, says they might with advantage have done so sooner.) The obvious drawback is that the government seems no better placed than the man in the street to chart a course for the more distant future.

Muddle about leadership has confused US policy on space since the beginning. It was a good wheeze, thirty years ago, that the US Navy thought of using its familiarity with military rocket technology to launch a civilian satellite (Vanguard) as part of the US contribution to the International Geophysical Year; the fact that the Soviet Sputnik came along a few months earlier had the United States worrying about leadership even before it had launched a rocket. In this meaning of the word, leadership means "prowess", the capacity to excel at everything. The Apollo project to send people to the Moon was directly inspired by the spurious sense of failure engendered by Sputnik but, against the odds, succeeded brilliantly both as a piece of exploration and in restoring falsely-injured pride. So why not abandon that dull work, and build a shuttle craft instead? That is how the logic ran just over a decade ago, which explains where the United States is now.

It is important that, even if the shuttle Challenger had not blown up in January 1986, those in the United States with an anxious frame of mind would still have been able to worry about lost leadership. There would have been the Hubble telescope (now waiting on the ground), it is true, but just look at that long list of record-breaking Soviet endurance flights! In retrospect, can it even have been wise to leave close encounters with Halley's comet to Europe and the Soviet Union? Can it be safe to let the French (who invented son et lumiere) make the running in space-based illuminations? What is the danger that some space power so far undeclared will embark on a project not yet thought of - quarrying the heat at the surface of Venus as a source of energy or simply putting a national flag around the planet? The trouble with these haunting speculations about what others may do is that their sheer variety is distracting. The quest for leadership through prowess is a recipe for doing a great many things, but none of them particularly well.

That, implicitly, is what the Ride report says. A decision now to send an expedition to Mars might satisfy the immediate wish to be seen to be doing something out of the ordinary, but would only add to the widespread sense of leadership lost if something should go wrong. Not that such a consequence is unavoidable. Indeed, the paradox in the depressed reaction of the United States to the Challenger accident is that there appear to be so many people who believe it shameful that there should be accidents even in projects as technically advanced as the shuttle. Leadership of this kind appears to equate with infallibility.

A wiser view is that leadership is not won by technological pyrotechnics (or by spending money), but must be earned. The United States space programme has done well in that respect over several decades. It has been open from the start, while the speed with which bright ideas have been turned into usable machines (telecommunications satellites again) has been an international public service. So too, in due course, will be the Hubble telescope. Where the programme has failed is in its tendency not to build on modest successes and even breathtaking successes. Some of those who turned up their noses at the Apollo programme may have regretted the retreat from the Moon. The humdrum exploration of the Solar System (without the help of people), while still substantial, has too often been skimped when the budget process has been rough. Yet those dull tasks may in the long run be better ways of earning respect abroad, and better ways of creating the depth of technical competence that will be needed for the long haul, than attempts to second guess the competition and outdo it. 